\title{
A COMPARISON OF PERFORMANCE RESULTS OF ARAS AND MOOSRA METHODS: AMERICAN CONTINENT COUNTRIES
}

DOI: 10.17261/Pressacademia.2020.1212

JEFA- V.7-ISS.2-2020(9)-p.173-186

Hakan Altin

Aksaray University Faculty of Economics And Administrative Sciences, Department of Business hakanaltin@aksaray.edu.tr, ORCID: 0000-0002-0012-0016

Date Received: April 4, 2020

Date Accepted: June 15, 2020

To cite this document

Altin, H., (2020). A Comparison Of Performance Results Of Aras And Moosra Methods: American Contitnent Countries Journal of Economics, Finance and Accounting (JEFA), V.7(2), p.173-186.

Permanent link to this document: $\mathrm{http}: / /$ doi.org/10.17261/Pressacademia.2020.1212

Copyright: Published by PressAcademia and limited licensed re-use rights only.

\section{ABSTRACT}

Purpose- The main aim of the study is to compare ARAS and MOOSRA performance results. For this, 2020 macroeconomic data of 31 countries in the Americas were used.

Methodology- In the study, CRITIC and ENTOPY methods were applied as weighting criteria with ARAS and MOOSRA methods.

Findings- Three important results were obtained from the application phase. First, the ARAS method with CRITIC and ENTOPY weighting criteria gives very close results in performance ranking. Therefore, in a study using ARAS method, there is no problem of selection between weighting criteria. Second, the MOOSRA method with CRITIC and ENTOPY weighting criteria gives very close results in performance ranking. Therefore, in a study using the MOOSRA method, there is no selection problem between the weighting criteria. Thirdly, ARAS and MOOSRA methods are very close to each other, performance ranking results.

Conclusion- Accordingly, the question of which of the two methods to choose in eliminating the multi-criteria decision making problem is eliminated. The results found are statistically significant.

Keywords: Multicriteria decision-making (MCDM) , CRITIC, ENTROPY, ARAS, MOOSRA

JEL Codes: C00, C02, G11

\section{ARAS VE MOOSRA YÖNTEMLERININ PERFORMANS SONUÇLARININ KARŞILAŞTIRILMASI: AMERIKA KITASI ÜLKELERI}

\section{ÖZET}

Amaç- Çalışmanın temel amacı ARAS VE MOOSRA performans sonuçlarının karşılaştııılmasıdır. Bunun için Amerika Kıtasında yer alan 31 ülkenin 2020 yılı makroekonomik verileri kullanılmıştır

Metodoloji- Çalışmada ağırlıklandırma ölçütleri olarak CRITIC ve ENTOPY yöntemleri ile ARAS ve MOOSRA metotları uygulanmıştır.

Bulgular- Uygulama aşamasından üç önemli sonuç elde edilmiştir. Birincisi, CRITIC ve ENTOPY ağırlıklandırma ölçütleriyle yapılan ARAS yöntemi performans sıralamasında birbirine çok yakın sonuçlar vermektedir. Dolayısıyla, ARAS yöntemi kullanılan bir çalışmada ağırlıklandırma ölçütleri arasında seçim problemi yaşanmaz. Íkincisi, CRITIC ve ENTOPY ağırlıklandırma ölçütleriyle yapılan MOOSRA yöntemi performans sıralamasında birbirine çok yakın sonuçlar vermektedir. Dolayısıyla, MOOSRA yöntemi kullanılan bir çalışmada ağılıklandırma ölçütleri arasında seçim problemi yaşanmaz. Üçüncüsü ARAS ve MOOSRA yöntemleri performans sıralama sonuçları birbirine çok yakındır. Sonuç- Buna göre, çok kriterli karar verme problemin çözümü şamasında iki yöntemden hangisinin seçileceği sorunu ortadan kalkar. Bulunan sonuçlar istatistiksel olarak anlamlıdır.

Anahtar Kelimeler: Çok Kriterli Karar Verme Yöntemleri(MCDM), CRITIC, ENTROPY, ARAS, MOOSRA JEL Kodları: C00, C02, G11 


\section{GiRiş}

Gerçek dünyadaki karar sorunlarının çözümleri birden fazla performans ölçütünü karşılamasını gerektirir. Bu hedefler genellikle birbiriyle çelişkilidir ve bir hedefte bir iyileşme başka bir hedefe zarar vermeden gerçekleştirilemez. Çok amaçlı bir problemde objektif olarak seçilebilecek tek bir çözüm yoktur; daha ziyade kriterler arasındaki farklı performans değişimlerini temsil eden bir dizi çözüm mevcuttur. Bu ortamda, karar vericilerin ödünleşmelerin olumlu bir şekilde çözülmesine ilişkin öznel tercihleri kullanılarak tek bir çözüm tanımlanabilir.

Çok amaçıı problemin kendisi, yönetişim düzenlemeleri, ölçütlerin formülasyonu ve ölçütlere karşı potansiyel çözümlerin değerlendirilmesi için modellerin belirtilmesi de dahil olmak üzere daha geniş bir karar alma sürecinde yer almaktadır. Karar analizinin en önemli tarafı ilgili herkes için neyi kabul ettikleri veya etmedikleri konusunda birbirlerini anlamalarına, katılmadıkları şeylere odaklanmasına ve daha iyi seçenekleri keşfetmesine yardımcı olmak konusunun keşfedilmesidir. İyi bir gerekçenin kişisel duygular, hisler, içgüdüler veya kültürel olarak spesifik, ahlaki kodlar ve normlardan bağımsız olması gerektiğine inanılmaktadır. Bu asgari değerler karşılanmazsa karar analizi doğru olarak değerlendirilmeyecektir.

Yöneylem Araştırması (Operations Research-OR), endüstriyel üretim sistemleri, hükümet ve sosyal programlar ve savunma sistemleri gibi organize sistemlerin yönetimine bilimsel yöntemin uygulanmasıdır. Aynı zamanda karar bilimi veya yönetim bilimi olarak adlandırılır. Başka bir ifadeyle, bilimin yönetimsel ve idari sorunların çözümüne uygulanmasıdır. Ayrı parçalarından ziyade bir bütün olarak alınan organize sistemlerin performansına odaklanır. Sonuç olarak, Yöneylem Araştırması bazı gerçek dünya hedeflerinin maksimum veya minimumlarının belirlenmesine odaklanan disiplinler arası bir yaklaşımdır.

Günümüz dünyasında kararların alınması gereken ortam daha fazla hiç olmadığı kadar karmaşıktır. Şirketler, piyasa değerlerini ve kârlarını en üst düzeye çıkarmak, kayıplarını ve risklerini kısıtlamak için yöntemler kullanır. Ayrıca, daha düşük maliyetlerle üretmek veya aynı maliyetlerle daha fazla miktar üretmek için araçlar tasarlarlar. Yöneylem Araştırması bunun için problem çözümü için uygun olan modeli oluşturur, optimal kriterinin seçilmesini sağlar tercih edilen çözümü bulur.

Yöneylem Araştırmaları içerisinde yer alan çok kriterli karar vermenin Multicriteria decision-making (MCDM) genel amacı, karar vericiye (Decision maker-DM), çoktan seçmeli kriterlerin ve farklı kriter önceliklerinin varlığı altında uygulanabilir seçim alternatiflerinin arasından en iyi alternatifin seçmesinde yardımcı olmaktır. Karar vermede seçim sorunu, tüm tarafların, bireylerin, kamu ve özel sektörün karşılaştığı en büyük sorundur. MCDM'ye göre sorun iki şekilde ortaya çıkar. Birincisi, karar alma sürecine dahil olan tarafların amaçlarına uygun seçim alternatiflerinin nasıl belirleneceğidir. İkincisi, en çok tercih edilen alternatifi belirlemek için alternatiflerin nasıl sıralanacağıdır.

Bu sorunun yanıtına ilişkin için çok sayıda MCDM yönteminin olduğu görülür. Göreceli olarak ARAS ve MOOSRA yöntemleri yenidir ve bu iki yöntemin performans sonuçları arasındaki ilişkinin ortaya konulması önemlidir. Çalışmada ağırlıklandırma ölçütleri olarak CRITIC ve ENTROPY yöntemleri kullanılmıştır. Otuz bir Amerika Kıtası ülkesinin makro ekonomik verilerinin karşılaştırıldığı çalışmada altı karar kriteri kullanılmıştır.

\section{LITERATÜR INCELEMESI}

ARAS ve MOOSRA yöntemlerine ilişkin literatür incelendiğinde iki önemli sonuca ulaşılmıştır. Birincisi, kuramsal temelli yapılan çalışmalardır. İkincisi, uygulama temelli yapılan çalışmalardır.

\subsection{ARAS}

Zavadskas and Turskis (2010a) çalışmasında insan faaliyetlerinin birçok alanında çok kriterli karar verme Multicriteria decisionmaking (MCDM) yöntemleri kullanıldığını söyler. Çok ölçütlü bir karar verme problemindeki her alternatif, bir dizi kriterle açıklanabilir. Kriterler nitel ve nicel olabilir. Genellikle farklı ölçü birimleri ve farklı bir optimizasyon yönü vardır. Normalizasyon, ölçüt değerlerinin karşılaştırılabilir ölçeklerini elde etmeyi amaçlamaktadır. Additive Ratio Assessment (ARAS) yöntemine göre, uygulanabilir bir alternatifin karmaşık verimliliğini belirleyen fayda fonksiyonu değeri, bir projede ele alınan ana kriterlerin değerlerinin ve ağırlıklarının göreceli etkisi ile doğru orantılıdır. Alternatiflerin öncelikleri, fayda fonksiyon değerine göre belirlenebilir. Alternatif fayda derecesi, analiz edilen değişkenin ideal olarak en iyisi ile karşılaştırılması ile belirlenir. ARAS yöntemi bunu mümkün kılar.

Zavadskas, Turskis, and Vilutiene, (2010b) çalışmasında geleneksel optimizasyonun, istatistiksel ve ekonometrik analiz yaklaşımlarında genellikle dikkate alınan sorunun iyi formüle edildiğidir. Karar vericilerin genellikle yürütülen analizin altında yatan tek bir hedeflerinin olduğunu değerlendirme kriterinin veya bakış açısının varsayıma dayandığını ileri sürmüştür. Böyle bir durumda problemlerinin çözümü kolayca elde edilebilir. Ancak gerçekte, problemlerinin modellenmesi konusunun, çoklu 
kriterlerin varlığına, karar vericinin değerlendirme sürecinin karmaşıklığına, öznel ve farklı doğasına ve birkaç karar vericinin katılımını dikkate alan farklı bir mantığa dayandığını iddia ederler. MCDM yöntemlerinin faydası karmaşık problemleri analiz etme sürecinde hem nicel hem de nitel kriterleri birleştirme kararında, karar vericinin karar verme sürecine katılmasına olanak sağlama ve karar verme sürecinde esnek bilimsel yöntemlerin uygulanması sırasında ortaya çıkar. Bu yöntemlerden biri olan ARAS yöntemi, alternatifin karmaşık verimliliğini belirleyen fayda fonksiyonu değerinin hesaplanmasında ve kriterlerin değerleri ile ağırlıklarının belirlemesinde yardımcı olur.

Stanujkic and Jovanovic (2012) çalışmasında İnternet kullanımındaki önemli artışın, şirketlerin iş yapma biçiminde ve diğer şirketler, hükümetler ve tüketicilerle etkileşimlerinde önemli değişikliklere neden olduğunu ileri sürerler. Fakülteler, hizmet veren kuruluşlar olarak, bu değişikliklerin yanı sıra web sitelerinin önemine de dikkat etmelidir. Çalışmalarında, ARAS yönteminin kullanımına dayalı olarak, bir fakülte Web sitesinin değerlendirilmesi için kullanımı kolay, çok kriterli bir karar alma modeli önermişlerdir. Fakülte web sitesi, çeşitli üniversiteler ve fakülteler arasında da bulunan rekabetçi bir ortamda çok önemlidir. Fakülte web sitesinin çeşitli amaçları vardır. Birincisi, aday öğrencilere bilgi sağlamak. İkincisi, öğrencilere bilgi sağlamaktır. Fakülte web sitelerinin tipik kullanıcılarının daha kesin tanımlamaları ile, ihtiyaçlarının daha kesin bir şekilde tanımlanması ve anahtar değerlendirme kriterlerinin öneminin daha kesin bir şekilde belirlenmesi, fakülte web sitelerinin kalitesinin daha hassas bir şekilde ölçülmesini sağlayacak MCDM - ARAS modeli oluşturulabilir.

Stanujkic (2015) çalışmasında ARAS yönteminin, aralıkıı bulanık sayıları (interval valued fuzzy numbers) kullanabilmesinden dolayı, gerçek dünya problemlerini çözmek için daha uygun olabileceğini ileri sürmektedir. Ayrıca, gerçek dünyadaki karar verme sorunlarının karmaşıklığının üstesinden gelebilmek için, linguistic değişkenlerin kullanımının yanı sıra grup kararı alma yaklaşımının da benimsenmesi gerektiğini söylemektedir. Aralıklı bulanık sayıların (interval-valued fuzzy numbers) kullanımı, karmaşık problemleri, özellikle de tahminle ilişkili problemleri çözme durumunda avantajlara sahip olduğunu söylemektedir. Bu nedenle, ARAS yönteminin etkili ve kullanımı kolay bir prosedürü olmasının yanı sıra, aralık değerli üçgen bulanık sayıların (interval-valued triangular futzy numbers) kullanımına olanak sağlaması dikkate değerdir. Bu çerçevede, ARAS yönteminin karmaşık karar verme problemlerinin, özellikle de bazı tahminlerle ilişkili problemlerin çözümünde önemli fırsatlar sağladığı sonucuna ulaşmıştır.

Turskis and Zavadskas (2010a) çalışmasında potansiyel bir tedarikçinin seçim sürecini anlatmaktadır. Bu seçim bir dizi kritere dayanmaktadır. Bu kriterler teslim fiyatı, finansal konum, üretim spesifikasyonları, standartlar ve ilgili sertifikalar ile ticari güç ve tedarikçinin performansıdır. Değerlendirme kriterleri ve önemi paydaşların çıkarları ve hedefleri dikkate alınarak seçilir. Problemin çözümü, (gri kriter puanlı) yeni bir Katkı Oranı Değerlendirme (ARAS) yöntemi - ARAS-G yöntemi uygulanarak yapılmıştır. ARAS yöntemi karmaşık dünya fenomenlerinin basit göreli karşılaştırmalar kullanılarak anlaşılabileceği argümanına dayanmaktadır. ARAS-G yöntemiyse özellikle nitel değişkenler hakkındaki kesinlik ve net veri eksikliği gidermek amacıyla gri değerlerle revize edilmiş bir yöntemdir. Yöntem kullanıcılar için, gri değerleri uygulayarak alternatifleri değerlendirmek ve sıralamak ve alternatif puanlarını mümkün olan en ideal alternatifle karşılaştırmak için yeni bir olanak sağlamaktadır. Deneysel sonuç önerilen yöntemin güvenilir olduğunu göstermektedir.

Dahooie, Zavadskas, Abolhasani, Vanaki, and Turskis (2018) çalışmasında sürdürülebilir kalkınma, çevresel etki ve insan refahı arasında bir denge bulmak, karmaşık sorunlarla başa çıkmak için amaçlar, riskler ve kısıtlamaları da içerisine alan yeni bir entegre model önermektedir. Uygulanan yöntemde optimal çözüm kavramı çok önemlidir. Model, literatürde yaygın olarak yer alan değişkenler kullanılarak oluşturulmuştur. Kademeli Ağırlık Değerlendirme Oranı Analizi Step-Wise Weight Assessment Ratio Analysis (SWARA) yöntemi ve Katkı Oranı Değerlendirmesi (ARAS) Additive Ratio Assessment yöntemleri bütünleştirilmiştir. Çalışma önerilen yöntemin yararlı ve alternatif bir karar verme yöntemi olduğunu göstermektedir.

Dadelo, Turskis, Zavadskas and Dadeliene (2012) çalışmasında güvenlik personelinin performansını (ARAS) yöntemiyle değerlendirmiştir. Personel performansını tahmin etmek karmaşık bir sorundur. Seçkin güvenlik çalışanlarının temel becerilerini açıklayan beş kriterden oluşan basit bir set kullanılmıştır. Oysa ki, işçilerin performansı birçok kriterle açıklanmalıdır. Ölçüt ağırlıkları ve kümeleri farklı durumlara ve araştırmanın niteliğine göre değişebilir. Kullanılan yöntem veya bilim politika yapmak için kullanıldığında, farklı paydaşları, katılımcıları, hedefleri ve bakış açılarını içeren kararların uygun bir şekilde yönetilmesini sağlar. Bu aynı zamanda tüm boyutları tek bir ölçü birliğine indirmenin imkansızlığını da ortadan kaldııır. Birden fazla kriter değerlendirmesi, ölçülemezlik ilkesinin uygulanması için güçlü bir çerçeve sağlar.

Reza and Majid (2013) çalışmasında online bankacılığa duyulan güvenin öncü göstergelerin ne olabileceğine dair kavramsal çerçeve ve operasyonel bir model sunulmuştur. ARAS kullanılarak, yapı ve karşılıkı ilişkiler tanınmakla kalmamış, güven konusunda online bankacılığa etki eden temel kriterler de belirlenmiştir. Bunun için ilk olarak, çevrimiçi bankacılık için güven konularının öncüllerine vurgu yapan yeni bir model geliştirilmiştir. İkincisi, sıralama ölçütlerinde ve alt ölçütlerinde yine ARAS yöntemi uygulamışlardır. ARAS yöntemi karmaşık ve iç içe geçmiş problemlerle başa çıkabilir ve seçimleri belirlenen kriterlere 
göre sıralayabilir. Sonuçlar, bu çalışmadaki en başarılı üç bankanın diğer bankalar için bir geçiş yolu olabileceğini göstermektedir.

Turskis and Zavadskas (2010b) çalışmasında lojistik merkezinin seçimi konusunda ARAS-F yöntemini uygulamışlardır. Lojistik merkezinin seçimi bir karar problemidir. Genel olarak MCDM'nin karar vermede sağladığı temel avantajlar karmaşık problemleri analiz etme olasılığı; değerlendirme sürecinde hem nicel hem de nitel kriterleri birleştirme olasıllı̆ıı; kararların iyi kanıtı olasılığı; karar vericinin karar verme sürecine aktif olarak katılma olasılığı ve karar verme sürecinde esnek bilimsel yöntemlerin uygulanabilmesidir. Çalışmanın amacı, bir dizi alternatif arasından lojistik merkezi için en uygun yeri seçmek, paydaşların belirsiz bir ortamda performans değerlendirmesine yardımcı olmak, kriterlerin öznelliğinin ve belirsizliğinin üçgen bulanık sayılarla tanımlanmasıdır. Yeni önerilen ARAS-F yöntemine göre, uygulanabilir bir alternatifin karmaşık verimliliğini belirleyen fayda fonksiyonu değeri, bir projede ele alınan ana kriterlerin değerlerinin ve ağılıklarının göreceli etkisi ile doğru orantılıdır. Buna göre Optimal bir alternatife sahip oranın alternatifleri sıralamak ve alternatif projeleri iyileştirmenin yollarını bulmak istediği durumlarda kullanılabilir.

Kutut, Zavadskas and Lazauskas (2013) and (2014) çalışmalarında kültürel miras binalarının kültürel varlıkların restorasyonu veya bakımı için öncelik konusunda en iyi yöntemi bulmayı amaçlamaktadır. Bu tür binaların rehabilitasyonu, kültürel mirasın yönetimi için geçerli olan karmaşık teknik belgeler ve metodolojilerle karşı karşıyadır. En rasyonel çözümler, büyük miktarda bilgiyi içeren ve değerlendiren bilimsel yöntemler uygulanarak sağlanabilir. En uygun alternatifi belirlemek için karmaşık AHP ve ARAS yöntemleri kullanılmıştır. Uzman tahminlerinin önemi AHP yöntemiyle değerlendirilirken en uygun alternatifin belirlenmesi için ARAS yöntemi uygulanmıştır. ARAS yöntemi, seçilen kriterlere ve göreceli önemlerine göre en yüksek fayda derecesine sahip alternatifin belirlenmesi için uygulanmıştır. Bu yöntemlerin bütünleşmesi, kültürel miras uzmanlarının, kamu temsilcilerinin ve yatırımcıların seçilen binaların her birine yönelik tutumlarının değerlendirilmesine olanak tanımıştır. Sonuç olarak, bu tür çok kriterli yöntemlerin kullanılması, bir proje uygulama çözümü seçimi ile ilgili karar alma sürecinde tüm paydaş gruplarının görüşlerinin dikkate alınmasına olanak tanır.

Karabašević, Paunkovic and Stanujkić (2016) çalışmasında SWARA VE ARAS yöntemleri kullanılarak şirketleri kurumsal sosyal sorumluluk sıralamasına tabi tutmuşlardır. Kurumsal sosyal sorumluluk çerçevesinde, kurumsal sektörler ve şirketler, şirketin topluma ve faaliyet gösterdikleri topluma karşı imaj ve sorumluluğunu artırmak için "kurumsal sosyal sorumluluk" stratejisinin uygulanmasının önemini kabul etmişlerdir. Çok uluslu şirketler günlük faaliyet ve operasyonlarında sürdürülebilir kurumsal sosyal sorumluluk modellerine daha fazla önem vermektedir. Çalışmanın odak noktası kurumsal sosyal sorumluluk göstergelerini belirlemek ve şirketleri göstergelere göre sıralamaktır. Değerlendirme ve sıralama için önerilen çerçeve SWARA ve ARAS yöntemleridir. Önerilen çerçevenin kullanılabilirliği ve etkinliği açıklayıcı bir örnekte gösterilmiştir.

\subsection{MOOSRA}

Jagadish and Ray (2014) çalışmasında MOOSRA yönteminin uygulamaları bir vaka çalışmasıyla gösterilmektedir. Tüm imalat endüstrilerinde çevresel meseleler çok önemlidir, çünkü üretim sürecinde ciddi bir sorun yaratır. Her üretim sürecinde, kesme sIVISı (cutting fluid) çevre kirliliğinin anahtar kaynağıdır. Yeşil üretim (green manufacturing-GM) için en uygun kesme sIVISı seçimi çevre kirliliğinin azaltılması için esastır. Geleneksel seçim için düşünülen objektif faktörler iki türdür. Maliyet ve kalite. Ancak yeşil faktörler de GM açısından dikkate alınmalıdır. Çalışmanın amacı, çevresel etkiyi, maliyeti en aza indiren ve kaliteyi en üst düzeye çıkaran en iyi kesme sıvısını seçmektir. Çalışma basit oran analizi (MOOSRA) temelinde çok amaçlı bir optimizasyon olan yeni bir yöntem sunmaktadır.

Sarkar, Panja, Das and Sarkar (2015) çalışmasında geleneksel olmayan makine seçiminde etkin bir karar destek sisteminin geliştirilmesi konusunu incelemişlerdir. Çalışmada, bir uzman grubundan toplanan bilgilerin öznel olarak değerlendirilmesinde MOORA ve MOOSRA yönteminin kullanılması benimsenmiştir. Diğer karar verme senaryolarına etkili bir şekilde uygulanabilen bir örnek olay incelemesi gösterilmiştir. Yöntemin, yöneticiler için hesaplama açısından çok basit, kolay anlaşılabilir olduğu aynı zamanda çok sayıda öznel özelliğe sahip olduğu düşünülmektedir. Yaptıkları çalışmayla sıralama değerlerinin, bir kuruluşun yöneticilerine, geleneksel olmayan bir makine seçmeleri için iyi rehberlik sağlaması gerektiğini beklenmektedirler. Ayrıca, geleneksel olmayan makine üreticileri için içsel bir öngörü sağlayacaktır.

Adalı and Işık (2017) çalışmasında dizüstü bilgisayar seçimini çok amaçlı karar verme sorunu MULTIMOORA ve MOOSRA yöntemleri ile ele almaktadırlar. Karar verme süreci, alternatifler için çelişen hedeflerin değerlerini ve karar vericilerin intiyaçlarına göre en iyi alternatifin seçilmesini gerektirir. Çok amaçlı optimizasyon yöntemleri bu seçim için çözüm sağlayabilir. MOORA yönteminin prosedürü, çeşitli kriterlere göre alternatiflerin genel performansını üretir. Ayrıca, seçim sürecinin öznel kısmını yansıtmaktadır. MOOSRA yöntemiyse, MOORA yönteminin tüm avantajlarına sahiptir. Buna ilaveten bazı önemli avantajları da vardır. En önemli avantajı sonuçların pozitif veya negatif olma olasılığını ortadan kaldırmasıdır. 
MULTIMOORA ve MOOSRA yöntemleri diğer karar verme problemlerinde olduğu gibi çok sayıda kriter ve alternatiflere uygulanabilme olanağı sağlar.

\section{3. ÇALIŞMANIN AMACI VE KAPSAMI}

Bu çalışmanın temel amacı Çok Kriterli Karar Verme Yöntemlerinden biri olan ARAS ve MOOSRA performans sıralama sonuçlarının karşılaştırılmasıdır. Çalışmada objektif ağırlıklandırma teknikleri (karar kriterlerin önem dereceleri) olarak CRITIC ve ENTROPY yöntemleri kullanılmıştır. Uygulama aşamasında Amerika Kıtasında yer alan 31 ülkenin 2020 yılı makroekonomik verileri kullanılmıştır. Bunlar; ekonomik büyüme (GDP Growth Rate (\%)), satın alma gücüne göre kişi başına milli gelir (GDP per Capita (PPP)), doğrudan yabancı yatırım (FDI Inflow (Millions)), işsizlik (Unemployment (\%)), enflasyon (Inflation (\%)) ve kamu borcu (Public Debt (\% of GDP)) verileridir. Çalışmada kullanılan veriler Ekonomik Özgürlük Endeks (Economic Freedom Index) sayfasından alınmıştır. Veriler arasındaki uyumu sağlamak için satın alma gücüne göre kişi başına milli gelir ve doğrudan yabancı yatırımların logaritması alınarak işleme konulmuştur. Kullanılan karar matrisi $31 * 6$ tipinde bir matristir.

\section{4. ÇALIŞMADA KULLANILAN YÖNTEMLER}

\subsection{ADDITIVE RATIO ASSESSMENT (ARAS) METHOD}

Bir MCDM problemi, her biri aynı anda dikkate alınması gereken farklı karar kriterleri açısından açıkça tanımlanmış olan sınırlı sayıda karar alternatifini sıralama göreviyle ilgilidir. ARAS yöntemine göre, uygulanabilir bir alternatifin karmaşık nispi etkinliğini belirleyen bir fayda fonksiyon değeri, ele alınan ana kriterlerin değer ve ağırlıklarının nispi etkisi ile doğru orantılıdır. Alternatiflerin öncelikleri, fayda fonksiyon değerine göre belirlenebilir. Bu yöntem kullanıldığında karar alternatiflerini değerlendirmek ve sıralamak mümkün olabilir. Alternatif fayda derecesi, analiz edilen değişkenin ideal olarak en iyisi ile karşılaştırılması ile belirlenir. Optimal bir alternatif ile oranın alternatifleri sıralamak ve alternatif projeyi iyileştirmenin yollarını bulmak istediği durumlarda kullanılabileceği söylenebilir. ARAS yöntemi, bir sıralama bulmak için optimallik derecesi kavramını kullanır. Her bir alternatife göre ölçütlerin normalleştirilmiş ağırlıklı değerlerinin toplamı, en iyi alternatifin normalleştirilmiş ağırıklı değerlerinin toplamına bölünmesiyle elde edilir. ARAS yöntemin metodolojik açıklamaları ve hesaplamaları için Zavadskas ve Turskis (2010a, s.159-172) ve Zavadskas, Turskis, ve Vilutiene, (2010b, s. 123-141) kullanılmıştır.

Adım 1. Karar verme matrisinin belirlenmesidir.

$$
X=\left(\begin{array}{ccc}
x_{01} & \cdots & x_{0 n} \\
\vdots & \ddots & \vdots \\
x_{m 1} & \cdots & x_{m n}
\end{array}\right) ; i=\overline{0, m} ; j=\overline{1, n} .
$$

$\mathrm{n}$, matris gösteriminde MCDM ile çözülmesi gereken herhangi bir problemi göstermektedir. $\mathrm{m}$ alternatifleri, $\mathrm{n}$ kriterleri göstermektedir.

J kriterinin optimal değeri bilinmiyorsa, o zaman, minimum ve maksimum değerleri için

$x_{0 j}=\max _{i} x_{i j}$, ĕger $\max _{i} x_{i j}$ tercih edilir.

$x_{0 j}=\min _{i} x_{i j}^{*}$, ĕger $\min _{i} x_{i j}^{*}$ tercih edilir.

Genellikle, xij performans değerleri ve wj ölçüt ağırıkları karar verme matrisinin (decision-making matrix-DMM) girdileri olarak görüntülenir. Bilgiler, ilgili taraflar tarafından hedefler ve fırsatlar dikkate alınarak düzeltilebilir.

Adım 2. Normalize Edilmiş Karar Matrisi Oluşturulur. Bunun için matris X'in Xij değerleri normalize edilir. 
$\bar{X}=\left(\begin{array}{ccc}\bar{x}_{01} & \ldots & \bar{x}_{0 n} \\ \vdots & \ddots & \vdots \\ \bar{x}_{m 1} & \ldots & \bar{x}_{m n}\end{array}\right) ; i=\overline{0, m ;} j=\overline{1, n}$

Buna göre tercih edilen değerleri maksimum olan kriterler aşağıdaki gibi normalleştirilir.

$$
\bar{X}_{i j}=\frac{x_{i j}}{\sum_{i=0}^{m} X_{i j}}
$$

Tercih edilen değerleri minimum olan kriterler iki aşamalı prosedür uygulanarak normalleştirilir.

$$
x_{i j}=\frac{1}{x_{i j}{ }^{*}} ; \bar{x}_{i j}=\frac{x_{i j}}{\sum_{i=0}^{m} X_{i j}}
$$

Adım 3. Normalleştirilmiş Ağırlıklı Matrisi tanımlanır.

$0<w j<1$ ağırlıklarıyla kriterleri değerlendirmek mümkündür. Sadece iyi yapılandırılmış ağırlıklar kullanılmalıdır çünkü ağırlıklar her zaman öznel ve çözümü etkiler. Ağırlık wj değerleri genellikle uzman değerlendirme yöntemi ile belirlenir. Wj ağırlıklarının toplamı 1'e eşittir.

$$
\sum_{j=1}^{n} w_{j}=1
$$

$$
\hat{X}=\left(\begin{array}{ccc}
\hat{x}_{01} & \ldots & \hat{x}_{0 n} \\
\vdots & \ddots & \vdots \\
\hat{x}_{m 1} & \cdots & \hat{x}_{m n}
\end{array}\right) ; i=\overline{0, m} ; j=\overline{1, n} .
$$

Tüm kriterlerin normalleştirilmiş ağırlıklı değerleri aşağıdaki gibi hesaplanır:

$$
\hat{x}_{i j}=\bar{x}_{i j} w_{j} ; i=\overline{0, m}
$$

burada wj, j ölçütünün ağırlığı (önemi) ve xij, j ölçütünün normalleştirilmiş derecelendirmesidir. Optimal fonksiyon değerleri şu şekilde belirlenir.

$$
S_{i}=\sum_{j=1}^{n} \hat{x}_{i j} ; i=\overline{0, m}
$$

burada Si, i alternatifinin optimallik fonksiyonunun değeridir.

En büyük değer en iyisidir ve en küçük olanı en kötüsüdür. Hesaplama işlemi göz önüne alındığında, Si optimallik fonksiyonunun, araştırılan kriterlerin Xij değerleri ve ağılıkları ile nihai sonuç üzerindeki göreceli etkisi ile doğrudan ve orantılı bir ilişkisi vardır. Bu nedenle, optimallik fonksiyonunun Si değeri ne kadar büyük olursa, alternatif o kadar etkili olur. 
Alternatiflerin öncelikleri Si değerine göre belirlenebilir. Sonuç olarak, bu yöntem kullanıldığında karar alternatiflerini değerlendirmek ve sıralamak mümkündür.

Alternatif fayda derecesi, analiz edilen değişkenin ideal olarak en iyi SO ile karşılaştırılmasıyla belirlenir. Alternatif bir ai'nin kullanım derecesi Ki'nin hesaplanması için kullanılan denklem aşağıda verilmiştir:

$$
K_{i}=\frac{S_{i}}{S_{0}} ; i=\overline{0, m}
$$

burada Si ve S0, Denklem (9) 'dan elde edilen optimallik kriter değerleridir. Hesaplanan Ki değerlerinin [0, 1] aralı̆̆ındadır.

\subsection{MULTI-OBJECTIVE OPTIMISATION ON THE BASIS OF SIMPLE RATIO ANALYSIS (MOOSRA) METHOD}

MOOSRA yönteminin temelinde MOORA yöntemi yer alır. MOOSRA yöntemi MOORA yöntemiyle benzer özellikler göstermektedir. Bu çevrede, MOORA yönteminin temel varsayımları MOOSRA yöntemi için de geçerlidir. Ancak MOORA ile karşılaştırıldığında daha güçlü bir açıklama gücüne sahiptir. MOORA yönteminde her bir alternatifin genel performans puanı, sırasıyla faydalı ve faydalı olmayan kriterlerin toplam puanları arasındaki farklar alınarak hesaplanır. Sonuçlar pozitif veya negatif olabilir. Negatif değerlerden kaçınmak için, MOOSRA yöntemi, faydalı ve faydalı olmayan kriterlerin genel puanlarının oranını kullanır. Böylece MOORA'da görünebilecek negatif performans puan olasılığı bu yöntemde görülmez. Ayrıca, MOOSRA yönteminde hesaplama süresi kısa matematiksel işlemler sayısı azdır. MOOSRA yöntemin metodolojik açıklamaları ve hesaplamaları için Jagadish ve Ray (2014, s. 559-563) kullanılmıştır.

Adım 1. Kriterlerin ve alternatiflerin listelendiği karar matrisinin oluşturulmasıyla başlar.

$$
X_{i j}=\left[\begin{array}{ccccccc}
X_{11} & X_{12} & X_{13} & \cdot & \cdot & \cdot & X_{1 m} \\
X_{21} & X_{22} & X_{23} & \cdot & \cdot & \cdot & X_{2 m} \\
X_{31} & X_{32} & X_{33} & \cdot & \cdot & \cdot & X_{3 m} \\
\cdot & \cdot & \cdot & \cdot & \cdot & \cdot & \cdot \\
\cdot & \cdot & \cdot & \cdot & \cdot & \cdot & \cdot \\
\cdot & \cdot & \cdot & \cdot & \cdot & \cdot & \cdot \\
X_{n 1} & X_{n 2} & X_{n 3} & \cdot & \cdot & \cdot & X_{n m}
\end{array}\right]
$$

Burada, ölçütler X1, X2, ..., Xn ile gösterilir.

Adım 2. Niteliklerin değerini 0-1 aralığına dönüştürme işlemine normalleştirme denir ve çok öznitelikli karar verme yöntemlerinde, bir karar matrisindeki farklı veri ölçüm birimleriyle performans derecelendirmesini uyumlu bir birime dönüştürmek gerekir. MOOSRA yönteminde bulanık karar matrisinin elemanları aşağıdaki denklem kullanılarak normalleştirilir.

$$
x_{i j}^{*}=\frac{x_{i j}}{\sqrt{\sum_{i=1}^{n} X_{i j}^{2}}}
$$

Burada, ölçüt değeri Xij'nin normalleştirilmiş performansı temsil eder.

Adım 3. Alternatiflerin Performansının Belirlenmesi.

Tüm alternatiflerin performans puanı Yi aşağıdaki denklem kullanılarak, faydalı kriterlerin ağırıklı toplamının, faydalı olmayan kriterlerin ağırlıklı toplamına basit oranı olarak hesaplanır. 
$Y_{i}=\frac{\sum_{j=1}^{g} W_{j} \mathbf{X}_{\mathrm{ij}}^{*}}{\sum_{j=g+1}^{g} W_{j} \mathbf{X}_{\mathrm{ij}}^{*}}$

Burada g maksimize edilecek karar değişkeni gösterirken (g-n) minimize dilecek değişkeni göstermektedir. Yi sıralaması, alternatiflerin sıralamasını gösterir.

Bazı durumlarda, özelliklerin eşit derecede önemli olduğunu düşünürsek, optimizasyon formülü

$Y_{i}=\frac{\sum_{j=1}^{g} X_{\mathrm{ij}}^{*}}{\sum_{j=g+1}^{g} X_{\mathrm{ij}}^{*}}$

\section{CRITIC VE ENTROPY TABANLI ARAS VE MOOSRA UYGULAMASI}

\subsection{ARAS YÖNTEMi ${ }^{1}$}

Uygulamanın ilk aşamasında karar matrisi oluşturulur. Karar matrisi Tablo 1'de gösterilmiştir. Karar matrisi 31 alternatiften ve 6 kriterden oluşan 31x6 tipinde bir matristir. Amaç fonksiyonunda kriterler C1; ekonomik büyüme, maksimum (GDP Growth Rate (\%)), C2; satın alma gücü paritesine göre kişi başına milli gelir, maksimum (GDP per Capita (PPP)), C3; doğrudan yabancı yatırım, maksimum (FDI Inflow (Millions)), C4; işsizlik, minimum (Unemployment (\%)), C5; enflasyon, minimum (Inflation (\%)), C6; kamu borcu, minimum Public Debt (\% of GDP) olarak belirlenmiştir. Optimal değerler olarak her bir kriterin maksimumsa en büyük değeri, minimumsa en küçük değeri kullanılmıştır. İkinci aşamada, normalize edilmiş karar matrisi değerleri elde edilmiştir. Üçüncü aşamada, ağırlıklı normalize karar matrisi elde edilmiştir. Dördüncü aşamada, optimal fonksiyon değerleri elde edilmiştir.

Tablo 2 çalışmada kullanılan CRITIC ve ENTROPY yöntemlerinden elde edilen kriter ağırlıklarını göstermektedir. Tablo 3 alternatiflerin CE-ARAS yöntemine göre aldıkları performans değerlerini göstermektedir. Tablo 4 alternatiflerin CE-ARAS yöntemi sıralama değerlerini göstermektedir. Tablo 4 incelendiğinde sıralama değerlerinin birbirine çok yakın olduğu görülür. Buna göre CARAS ve EARAS yöntemlerine göre en iyi sıralama performansı gösteren ilk beş ülke sırasıyla Belize, Panama, Peru, Guantemala ve Donika ülkeleridir.

\section{Tablo 1: Karar Matrisi: Ham Veriler}

\begin{tabular}{|l|c|c|c|c|c|c|}
\hline Ülkeler & C1 & C2 & C3 & C4 & C5 & C6 \\
\hline Arjantin & $-2,5$ & 4,3 & 4,1 & 9,5 & 34,3 & 86,3 \\
\hline Bahama & 2,3 & 4,5 & 3,0 & 11,9 & 2,2 & 61,0 \\
\hline Barbados & $-0,5$ & 4,3 & 2,3 & 9,6 & 3,6 & 124,5 \\
\hline Belize & 3,0 & 3,9 & 2,1 & 9,4 & 0,3 & 94,8 \\
\hline Bolivya & 4,3 & 3,9 & 2,4 & 3,3 & 2,3 & 53,9 \\
\hline Brezilya & 1,1 & 4,2 & 4,8 & 12,5 & 3,7 & 87,9 \\
\hline Kanada & 1,8 & 4,7 & 4,6 & 5,9 & 0,9 & 90,6 \\
\hline Şili & 4,0 & 4,4 & 3,9 & 7,2 & 2,3 & 25,6 \\
\hline Kolombiya & 2,7 & 4,2 & 4,0 & 9,1 & 3,2 & 50,5 \\
\hline
\end{tabular}

${ }^{1}$ Çok kriterli karar verme yöntemleri çok sayıda sıralı matris çarpımına dayanmaktadır. Çalışmada 31x6 tipinde bir matris kullanılmıştır. Her işlemde buna ilişkin bir matris formunun çalışmaya eklenmesi çalışmada çok yer kaplamaktadır. Bu yüzden sonuç matrislerine yer verilmiştir. 


\begin{tabular}{|l|l|l|l|l|l|l|} 
Kosta Rika & 2,7 & 4,2 & 3,3 & 8,1 & 2,3 & 53,5 \\
\hline Küba & 2,3 & 4,1 & 3,2 & 2,3 & 6,9 & 51,0 \\
\hline Donika & $-12,0$ & 4,0 & 1,6 & 0,0 & 1,4 & 83,1 \\
\hline Dominik Cumhuriyeti & 7,0 & 4,3 & 3,4 & 5,8 & 3,6 & 41,6 \\
\hline Ekvator & 1,1 & 4,1 & 3,1 & 3,9 & $-0,2$ & 46,1 \\
\hline El Salvador & 2,5 & 3,9 & 2,9 & 4,4 & 1,1 & 67,1 \\
\hline Guatemala & 3,1 & 3,9 & 3,0 & 2,7 & 3,8 & 24,5 \\
\hline Guyana & 3,4 & 3,9 & 2,7 & 12,2 & 1,3 & 57,0 \\
\hline Haiti & 1,5 & 3,3 & 2,0 & 13,5 & 13,5 & 33,0 \\
\hline Honduras & 3,7 & 3,7 & 3,1 & 4,1 & 4,3 & 40,3 \\
\hline Jamaika & 1,4 & 4,0 & 2,9 & 9,5 & 3,7 & 99,4 \\
\hline Meksika & 2,0 & 4,3 & 4,5 & 3,3 & 4,9 & 53,6 \\
\hline Nikaragua & $-4,0$ & 3,8 & 2,6 & 4,5 & 5,0 & 37,2 \\
\hline Panama & 3,9 & 4,4 & 3,7 & 3,9 & 0,8 & 39,4 \\
\hline Paraguay & 3,7 & 4,1 & 2,7 & 4,7 & 4,0 & 21,6 \\
\hline Peru & 4,0 & 4,2 & 3,8 & 2,8 & 1,3 & 26,8 \\
\hline Saint Lucia & 1,0 & 4,2 & 2,1 & 20,9 & 1,9 & 66,8 \\
\hline Saint Vincent ve Grenadines & 2,0 & 4,1 & 2,0 & 19,8 & 2,4 & 73,1 \\
\hline Suriname & 2,0 & 4,2 & 2,3 & 7,6 & 6,9 & 69,6 \\
\hline Trinidad ve Tobago & 0,3 & 4,5 & 2,6 & 2,8 & 1,1 & 45,3 \\
\hline Amerika Birleşik Devletleri & 2,9 & 4,8 & 5,4 & 3,9 & 2,4 & 105,8 \\
\hline Uruguay & 2,1 & 4,4 & 2,8 & 8,0 & 7,6 & 70,0 \\
\hline & & & & & \\
\hline
\end{tabular}

\section{Tablo 2: Critic ve Entropy Ağırlık Değerleri}

\begin{tabular}{|l|l|l|l|l|l|l|}
\hline CRITIC W & 0,1929 & 0,1482 & 0,1486 & 0,1710 & 0,1747 & 0,1647 \\
\hline ENTOPY W & 0,1598 & 0,1670 & 0,1672 & 0,1682 & 0,1703 & 0,1675 \\
\hline
\end{tabular}

Tablo 3: Alternatiflerin CE-ARAS Yöntemine Göre Aldıkları Performans Değerleri

\begin{tabular}{|l|c|c|l|c|c|}
\hline CRITIC ARAS & $\mathbf{S i}$ & $\mathbf{K i}$ & ENTROPY ARAS & $\mathbf{~} \mathbf{i}$ & $\mathbf{~} \mathbf{i}$ \\
\hline Arjantin & 0,892 & 0,229 & Arjantin & 1,129 & 0,281 \\
\hline Bahama & 1,043 & 0,268 & Bahama & 1,510 & 0,376 \\
\hline Barbados & 0,676 & 0,173 & Barbados & 0,999 & 0,249 \\
\hline Belize & 2,417 & 0,620 & Belize & 4,308 & 1,073 \\
\hline Bolivya & 1,327 & 0,340 & Bolivya & 2,035 & 0,507 \\
\hline Brezilya & 0,946 & 0,243 & Brezilya & 1,275 & 0,317 \\
\hline Kanada & 1,479 & 0,379 & Kanada & 2,287 & 0,569 \\
\hline Şili & 1,470 & 0,377 & Şili & 2,208 & 0,550 \\
\hline Kolombiya & 1,113 & 0,285 & Kolombiya & 1,572 & 0,392 \\
\hline Kosta Rika & 1,132 & 0,290 & Kosta Rika & 1,655 & 0,412 \\
\hline
\end{tabular}




\begin{tabular}{|l|l|l|l|l|l|} 
Küba & 1,287 & 0,330 & Küba & 2,002 & 0,499 \\
\hline Donika & 1,490 & 0,382 & Donika & 1,970 & 0,491 \\
\hline Dominik Cumhuriyeti & 1,416 & 0,363 & Dominik Cumhuriyeti & 1,968 & 0,490 \\
\hline Ekvator & $-1,231$ & $-0,316$ & Ekvator & $-2,954$ & $-0,736$ \\
\hline El Salvador & 1,390 & 0,356 & El Salvador & 2,225 & 0,554 \\
\hline Guatemala & 1,510 & 0,387 & Guatemala & 2,425 & 0,604 \\
\hline Guyana & 1,227 & 0,315 & Guyana & 1,864 & 0,464 \\
\hline Haiti & 0,806 & 0,207 & Haiti & 1,214 & 0,302 \\
\hline Honduras & 1,232 & 0,316 & Honduras & 1,841 & 0,459 \\
\hline Jamaika & 0,829 & 0,213 & Jamaika & 1,168 & 0,291 \\
\hline Meksika & 1,252 & 0,321 & Meksika & 1,850 & 0,461 \\
\hline Nikaragua & 1,198 & 0,307 & Nikaragua & 1,791 & 0,446 \\
\hline Panama & 1,878 & 0,482 & Panama & 3,039 & 0,757 \\
\hline Paraguay & 1,412 & 0,362 & Paraguay & 2,209 & 0,550 \\
\hline Peru & 1,822 & 0,467 & Peru & 2,932 & 0,730 \\
\hline Saint Lucia & 0,874 & 0,224 & Saint Lucia & 1,325 & 0,330 \\
\hline Saint Vincent ve Grenadines & 0,858 & 0,220 & Saint Vincent ve Grenadines & 1,251 & 0,311 \\
\hline Suriname & 0,841 & 0,216 & Suriname & 1,189 & 0,296 \\
\hline Trinidad ve Tobago & 1,489 & 0,382 & Trinidad ve Tobago & 2,540 & 0,633 \\
\hline Amerika Birleşik Devletleri & 1,353 & 0,347 & Amerika Birleşik Devletleri & 1,915 & 0,477 \\
\hline Uruguay & 0,879 & 0,225 & Uruguay & 1,213 & 0,302 \\
\hline & & & & 0 \\
\hline
\end{tabular}

Tablo 4: Alternatiflerin CE-ARAS Yöntem Sıralama Değerleri

\begin{tabular}{|l|c|c|l|c|c|}
\hline \multicolumn{7}{|l}{ CARAS-Ki: SIRALAMA } & \multicolumn{2}{l}{ EARAS-Ki: SIRALAMA } \\
\hline Belize & 0,620 & 1 & Belize & 0,612 & 1 \\
\hline Panama & 0,482 & 2 & Panama & 0,470 & 2 \\
\hline Peru & 0,467 & 3 & Peru & 0,455 & 3 \\
\hline Guatemala & 0,387 & 4 & Donika & 0,400 & 4 \\
\hline Donika & 0,382 & 5 & Guatemala & 0,374 & 5 \\
\hline Trinidad ve Tobago & 0,382 & 6 & Şili & 0,364 & 6 \\
\hline Kanada & 0,379 & 7 & Trinidad ve Tobago & 0,364 & 7 \\
\hline Şili & 0,377 & 8 & Kanada & 0,362 & 8 \\
\hline Dominik Cumhuriyeti & 0,363 & 9 & Dominik Cumhuriyeti & 0,361 & 9 \\
\hline Paraguay & 0,362 & 10 & Paraguay & 0,351 & 10 \\
\hline El Salvador & 0,356 & 11 & El Salvador & 0,346 & 11 \\
\hline ABD & 0,347 & 12 & Bolivya & 0,335 & 12 \\
\hline Bolivya & 0,340 & 13 & ABD & 0,330 & 13 \\
\hline Küba & 0,330 & 14 & Küba & 0,317 & 14 \\
\hline Meksika & 0,321 & 15 & Honduras & 0,307 & 15 \\
\hline
\end{tabular}




\begin{tabular}{|l|l|l|l|l|l|} 
Honduras & 0,316 & 16 & Guyana & 0,307 & 16 \\
\hline Guyana & 0,315 & 17 & Meksika & 0,304 & 17 \\
\hline Nikaragua & 0,307 & 18 & Nikaragua & 0,300 & 18 \\
\hline Kosta Rika & 0,290 & 19 & Kosta Rika & 0,278 & 19 \\
\hline Kolombiya & 0,285 & 20 & Kolombiya & 0,272 & 20 \\
\hline Bahama & 0,268 & 21 & Bahama & 0,255 & 21 \\
\hline Brezilya & 0,243 & 22 & Brezilya & 0,224 & 22 \\
\hline Arjantin & 0,229 & 23 & Arjantin & 0,216 & 23 \\
\hline Uruguay & 0,225 & 24 & Uruguay & 0,214 & 24 \\
\hline Saint Lucia & 0,224 & 25 & Saint Lucia & 0,212 & 25 \\
\hline Saint Vincent Grenadines & 0,220 & 26 & Saint Vincent Grenadines & 0,211 & 26 \\
\hline Suriname & 0,216 & 27 & Suriname & 0,205 & 27 \\
\hline Jamaika & 0,213 & 28 & Jamaika & 0,200 & 28 \\
\hline Haiti & 0,207 & 29 & Haiti & 0,196 & 29 \\
\hline Barbados & 0,173 & 30 & Barbados & 0,157 & 30 \\
\hline Ekvator & $-0,316$ & 31 & Ekvator & $-0,329$ & 31 \\
\hline
\end{tabular}

\subsection{MOOSRA YÖNTEMI}

Uygulamanın ilk aşamasında karar matrisi oluşturulur. Karar matrisi Tablo 1'de gösterilmiştir. Karar matrisi 31 alternatiften ve 6 kriterden oluşan 31×6 tipinde bir matristir. İkinci aşamada, karar matrisi normalize edilmiştir. Üçüncü aşamada, ağırlıklı normalize edilmiş karar matrisi elde edilmiştir. Dördüncü aşamada, alternatiflerin MOOSRA yöntemine göre sıralanması yapılmıştır. Tablo 5 alternatiflerin CE- MOOSRA Yöntemine Göre Aldıkları Performans Değerleri göstermektedir. Tablo 6 alternatiflerin CE-MOOSRA yöntemine göre aldıkları sıralama değerlerini göstermektedir. Tablo 6 incelendiğinde sıralama değerlerinin birbirine çok yakın olduğu görülür. Buna göre CMOOSRA ve EMOOSRA yöntemlerine göre en iyi sıralama performansı gösteren ilk beşülke sırasıyla Peru, Donika, Panama, Dominik ve Guatemala ülkeleridir.

Tablo 5: Alternatiflerin CE-MOOSRA Yöntemine Göre Aldıkları Performans Değerleri

\begin{tabular}{|l|c|c|c|l|c|c|c|}
\hline CRITIC MOOSRA & $\mathbf{g}$ & $\mathbf{g}+\mathbf{1}$ & $\mathbf{Y i}$ & ENTROPY MOOSRA & $\mathbf{g}$ & $\mathbf{g + 1}$ & $\mathbf{Y i}$ \\
\hline Arjantin & 0,02 & 0,14 & 0,12 & Arjantin & 0,13 & 0,15 & 0,85 \\
\hline Bahama & 0,01 & 0,02 & 0,80 & Bahama & 0,01 & 0,03 & 0,18 \\
\hline Barbados & 0,01 & 0,03 & 0,28 & Barbados & 0,02 & 0,03 & 0,59 \\
\hline Belize & 0,01 & 0,02 & 0,61 & Belize & 0,01 & 0,03 & 0,39 \\
\hline Bolivya & 0,02 & 0,00 & 3,19 & Bolivya & 0,00 & 0,02 & 0,20 \\
\hline Brezilya & 0,02 & 0,02 & 0,72 & Brezilya & 0,01 & 0,04 & 0,29 \\
\hline Kanada & 0,02 & 0,01 & 1,37 & Kanada & 0,01 & 0,03 & 0,34 \\
\hline Şili & 0,02 & 0,01 & 3,91 & Şili & 0,00 & 0,02 & 0,05 \\
\hline Kolombiya & 0,02 & 0,01 & 1,54 & Kolombiya & 0,00 & 0,03 & 0,16 \\
\hline Kosta Rika & 0,01 & 0,01 & 1,53 & Kosta Rika & 0,00 & 0,02 & 0,18 \\
\hline Küba & 0,01 & 0,01 & 1,41 & Küba & 0,01 & 0,02 & 0,40 \\
\hline Donika & 0,07 & 0,01 & 8,53 & Donika & 0,01 & 0,08 & 0,10 \\
\hline Dominik Cumhuriyeti & 0,03 & 0,01 & 5,77 & Dominik Cumhuriyeti & 0,00 & 0,04 & 0,09 \\
\hline Ekvator & 0,01 & 0,00 & 2,59 & Ekvator & 0,00 & 0,01 & 0,20 \\
\hline
\end{tabular}




\begin{tabular}{|l|c|c|c|l|l|l|l|} 
El Salvador & 0,01 & 0,01 & 1,59 & El Salvador & 0,01 & 0,02 & 0,31 \\
\hline Guatemala & 0,01 & 0,00 & 4,83 & Guatemala & 0,00 & 0,02 & 0,14 \\
\hline Guyana & 0,01 & 0,01 & 0,88 & Guyana & 0,00 & 0,03 & 0,15 \\
\hline Haiti & 0,01 & 0,03 & 0,18 & Haiti & 0,02 & 0,04 & 0,51 \\
\hline Honduras & 0,01 & 0,01 & 2,86 & Honduras & 0,00 & 0,02 & 0,20 \\
\hline Jamaika & 0,01 & 0,02 & 0,45 & Jamaika & 0,01 & 0,03 & 0,47 \\
\hline Meksika & 0,02 & 0,01 & 2,41 & Meksika & 0,01 & 0,02 & 0,26 \\
\hline Nikaragua & 0,01 & 0,01 & 2,56 & Nikaragua & 0,00 & 0,02 & 0,21 \\
\hline Panama & 0,02 & 0,00 & 6,22 & Panama & 0,00 & 0,02 & 0,09 \\
\hline Paraguay & 0,01 & 0,00 & 3,85 & Paraguay & 0,00 & 0,02 & 0,12 \\
\hline Peru & 0,02 & 0,00 & 11,68 & Peru & 0,00 & 0,02 & 0,05 \\
\hline Saint Lucia & 0,01 & 0,04 & 0,20 & Saint Lucia & 0,01 & 0,04 & 0,13 \\
\hline Saint Vincent ve Grenadines & 0,01 & 0,04 & 0,23 & Saint Vincent ve Grenadines & 0,01 & 0,04 & 0,16 \\
\hline Suriname & 0,01 & 0,01 & 0,61 & Suriname & 0,01 & 0,02 & 0,45 \\
\hline Trinidad ve Tobago & 0,01 & 0,00 & 2,76 & Trinidad ve Tobago & 0,00 & 0,01 & 0,22 \\
\hline Amerika Birleşik Devletleri & 0,02 & 0,02 & 1,52 & Amerika Birleşik Devletleri & 0,01 & 0,04 & 0,37 \\
\hline Uruguay & 0,01 & 0,02 & 0,66 & Uruguay & 0,01 & 0,03 & 0,43 \\
\hline
\end{tabular}

Tablo 6: Alternatiflerin CE-MOOSRA Yöntem Sıralama Değerleri

\begin{tabular}{|l|c|c|l|c|c|}
\hline \multicolumn{2}{|l|}{ CMOOSRA-Yi: SIRALAMA } & \multicolumn{2}{l}{ EMOOSRA-Yi: SIRALAMA } & 11,413 & 1 \\
\hline Peru & 11,683 & 1 & Peru & 8,159 & 2 \\
\hline Donika & 8,526 & 2 & Donika & 6,089 & 3 \\
\hline Panama & 6,219 & 3 & Panama & 5,548 & 4 \\
\hline Dominik Cumhuriyeti & 5,766 & 4 & Dominik Cumhuriyeti & 4,694 & 5 \\
\hline Guatemala & 4,825 & 5 & Guatemala & 3,817 & 6 \\
\hline Şili & 3,911 & 6 & Şili & 3,736 & 7 \\
\hline Paraguay & 3,855 & 7 & Paraguay & 3,091 & 8 \\
\hline Bolivya & 3,185 & 8 & Bolivya & 2,780 & 9 \\
\hline Honduras & 2,862 & 9 & Honduras & 2,752 & 10 \\
\hline Trinidad ve Tobago & 2,764 & 10 & Trinidad ve Tobago & 2,574 & 11 \\
\hline Ekvator & 2,590 & 11 & Ekvator & 2,474 & 12 \\
\hline Nikaragua & 2,560 & 12 & Nikaragua & 2,373 & 13 \\
\hline Meksika & 2,406 & 13 & Meksika & 1,565 & 14 \\
\hline El Salvador & 1,589 & 14 & El Salvador & 1,514 & 15 \\
\hline Kolombiya & 1,538 & 15 & Kolombiya & 1,509 & 16 \\
\hline Kosta Rika & 1,529 & 16 & Amerika Birleşik Devletleri & 1,503 & 17 \\
\hline Amerika Birleşik Devletleri & 1,525 & 17 & Kosta Rika & 1,380 & 18 \\
\hline Küba & 1,410 & 18 & Küba & 1,356 & 19 \\
\hline Kanada & 1,366 & 19 & Kanada & \\
\hline
\end{tabular}




\begin{tabular}{|l|l|l|l|l|l|} 
Guyana & 0,885 & 20 & Guyana & 0,863 & 20 \\
\hline Bahama & 0,800 & 21 & Bahama & 0,788 & 21 \\
\hline Brezilya & 0,720 & 22 & Brezilya & 0,715 & 22 \\
\hline Uruguay & 0,662 & 23 & Uruguay & 0,650 & 23 \\
\hline Belize & 0,612 & 24 & Belize & 0,598 & 24 \\
\hline Suriname & 0,606 & 25 & Suriname & 0,595 & 25 \\
\hline Jamaika & 0,453 & 26 & Jamaika & 0,449 & 26 \\
\hline Barbados & 0,279 & 27 & Barbados & 0,278 & 27 \\
\hline Saint Vincent ve Grenadines & 0,234 & 28 & Saint Vincent ve Grenadines & 0,230 & 28 \\
\hline Saint Lucia & 0,196 & 29 & Saint Lucia & 0,194 & 29 \\
\hline Haiti & 0,178 & 30 & Haiti & 0,174 & 30 \\
\hline Arjantin & 0,116 & 31 & Arjantin & 0,113 & 31 \\
\hline
\end{tabular}

\section{CE-ARAS VE CE-MOOSRA YÖNTEMLERININ PERFORMANS SONUÇLARININ KARŞILAŞTIRILMASI}

Bu karşılaştırmanın yapılabilmesi için uygulama sonucundan elde edilen performans değerleri Spearman Korelasyon yaklaşımıyla incelenmiştir. Bu ilişki Tablo 7'de gösterilmiştir. Tablo 7 incelendiğinde kullanılan yöntemler ve elde edilen değerler arasında pozitif yönlü kuvvetli bir ilişkinin varlığı görülür. Buna göre ARAS ve MOOSRA yöntemlerinin performans sıralama sonuçları birbirlerine çok yakın sonuçlar vermektedir. Aralarında tam korelasyon ilişkisi vardır. Bu durum iki yöntemin bir biri yerine kullanılabileceğini göstermektedir. Bulunan sonuçlar istatistiksel olarak anlamlıdır.

Tablo 7: Performans Değerleri Arasındaki i̇lişki

\begin{tabular}{|c|c|c|c|c|c|c|}
\hline \multicolumn{7}{|c|}{ Korelasyonlar } \\
\hline & & & CARAS & EARAS & CMOOSRA & EMOOSRA \\
\hline \multirow[t]{12}{*}{ Spearman's rho } & \multirow[t]{3}{*}{ CARAS } & Korelasyon katsayısı & 1.000 & $1.000^{* *}$ & $1.000^{* *}$ & $1.000^{* *}$ \\
\hline & & Sig. (2-tailed) & . & .000 & .000 & .000 \\
\hline & & $\mathrm{N}$ & 31 & 31 & 31 & 31 \\
\hline & \multirow[t]{3}{*}{ EARAS } & Korelasyon katsayısı & $1.000^{* *}$ & 1.000 & $1.000^{* *}$ & $1.000^{* *}$ \\
\hline & & Sig. (2-kuyruklu) & .000 & . & .000 & .000 \\
\hline & & $\mathrm{N}$ & 31 & 31 & 31 & 31 \\
\hline & \multirow[t]{3}{*}{ CMOOSRA } & Korelasyon katsayısı & $1.000^{* *}$ & $1.000^{* *}$ & 1.000 & $1.000^{* *}$ \\
\hline & & Sig. (2-kuyruklu) & .000 & .000 & & \\
\hline & & $\mathrm{N}$ & 31 & 31 & 31 & 31 \\
\hline & \multirow[t]{3}{*}{ EMOOSRA } & Korelasyon katsayısı & $1.000^{* *}$ & $1.000^{* *}$ & $1.000^{* *}$ & 1.000 \\
\hline & & Sig. (2-kuyruklu) & .000 & .000 & . & \\
\hline & & $\mathrm{N}$ & 31 & 31 & 31 & 31 \\
\hline
\end{tabular}




\section{SONUC}

Çalışmanın temel amacı çok kriterli karar verme yöntemleri arasında yer alan ARAS VE MOOSRA yöntemlerinin performans sonuçlarının karşılaştııılmasıdır. Çalışmada ağırlıklandırma ölçütleri olarak CRITIC ve ENTOPY yöntemleri uygulanmıştır. Uygulama aşamasından üç önemli sonuç elde edilmiştir. Birincisi, CRITIC ve ENTOPY ağırlıklandırma ölçütleriyle yapılan ARAS yöntemi performans sıralamasında birbirine çok yakın sonuçlar vermektedir. Dolayısıyla, ARAS yöntemi kullanılan bir çalışmada ağırlıklandırma ölçütleri arasında seçim problemi yaşanmaz. İkincisi, CRITIC ve ENTOPY ağılıklandırma ölçütleriyle yapılan MOOSRA yöntemi performans sıralamasında birbirine çok yakın sonuçlar vermektedir. Dolayısıyla, MOOSRA yöntemi kullanılan bir çalışmada ağılıklandırma ölçütleri arasında seçim problemi yaşanmaz. Üçüncüsü ARAS ve MOOSRA yöntemleri performans sıralama sonuçları birbirine çok yakındır. Aralarında tam korelasyon ilişkisi vardır. Buna göre, çok kriterli karar verme problemin çözümü şamasında iki yöntemden hangisinin seçileceği sorunu ortadan kalkar. Bulunan sonuçlar istatistiksel olarak anlamlıdır.

\section{KAYNAKÇA}

Adalı, E. A., \& Işık, A. T. (2017). The Multi-Objective Decision Making Methods Based on MULTIMOORA and MOOSRA for the Laptop Selection Problem. Journal of Industrial Engineering International, 13(2), 229-237. DOI 10.1007/s40092-016-0175-5

Dadelo, S., Turskis, Z., Zavadskas, E. K., \& Dadeliene, R. (2012). Multiple Criteria Assessment of Elite Security Personal on the Basis of ARAS and Expert Methods. Economic Computation and Economic Cybernetics Studies and Research, 46(4), 65-88.

Dahooie, J. H., Zavadskas, E. K., Abolhasani, M., Vanaki, A., \& Turskis, Z. (2018). A Novel Approach for Evaluation of Projects Using an IntervalValued Fuzzy Additive Ratio Assessment (ARAS) Method: A Case Study of Oil and Gas Well Drilling Projects. Symmetry, $10(2), 45$. DOI:10.3390/sym10020045

Jagadish \& Ray, A. (2014). Green Cutting Fluid Selection Using MOOSRA Method. International Journal of Research in Engineering and Technology. 3(3), 559-563.

Karabašević, D., Paunkovic, J., \& Stanujkić, D. (2016). Ranking of Companies According to the Indicators of Corporate Social Responsibility Based on SWARA and ARAS Methods. Serbian Journal of Management, 11(1), 43-53. DOI:10.5937/sjm11-7877

Kutut, V., Zavadskas, E. K., \& Lazauskas, M. (2013). Assessment of Priority Options for Preservation of Historic City Centre Buildings Using MCDM (ARAS). Procedia Engineering, 57, 657-661. DOI: 10.1016/j.proeng.2013.04.083

Kutut, V., Zavadskas, E. K., \& Lazauskas, M. (2014). Assessment of Priority Alternatives for Preservation of Historic Buildings Using Model Based on ARAS and AHP Methods. Archives of Civil and Mechanical Engineering, 14(2), 287-294. DOI.org/10.1016/j.acme.2013.10.007

Reza, S., \& Majid, A. (2013). Ranking Financial Institutions Based on of Trust in online Banking Using ARAS and ANP Method. International Research Journal of Applied and Basic Sciences, 6(4), 415-423.

Sarkar, A., Panja, S. C., Das, D., \& Sarkar, B. (2015). Developing an Efficient Decision Support System for Non-Traditional Machine Selection: An Application of MOORA and MOOSRA. Production \& Manufacturing Research, 3(1), 324-342. DOI.org/10.1080/21693277.2014.895688

Stanujkic, D. (2015). Extension of the ARAS Method for Decision-Making Problems with Interval-Valued Triangular Fuzzy Numbers. Informatica, 26(2), 335-355. DOI.org/10.15388/Informatica.2015.51

Stanujkic, D., \& Jovanovic, R. (2012). Measuring a Quality of Faculty Website Using ARAS Method. In Proceeding of the International Scientific Conference Contemporary Issues in Business, Management and Education (pp. 545-554). DOI.10.3846/cibme.2012.45

Turskis, Z., \& Zavadskas, E. K. (2010a). A Novel Method for Multiple Criteria Analysis: Grey Additive Ratio Assessment (ARAS-G) method. Informatica, 21(4), 597-610.

Turskis, Z., \& Zavadskas, E. K. (2010b). A New Fuzzy Additive Ratio Assessment Method (ARAS-F). Case Study: The Analysis of Fuzzy Multiple Criteria in order to Select the Logistic Senters Location. Transport, 25(4), 423-432. DOI.org/10.3846/transport.2010.52

Zavadskas, E. K., \& Turskis, Z. (2010a). april A New Additive Ratio Assessment (ARAS) Method in Multicriteria Decision-Making. Technological and Economic Development of Economy, 16(2), 159-172. DOI. 10.3846/tede.2010.10

Zavadskas, E. K., Turskis, Z., \& Vilutiene, T. (2010b). Multiple Criteria Analysis of Foundation Instalment Alternatives by Applying Additive Ratio Assessment (ARAS) Method. Archives of Civil and Mechanical Engineering, 10(3), 123-141. 